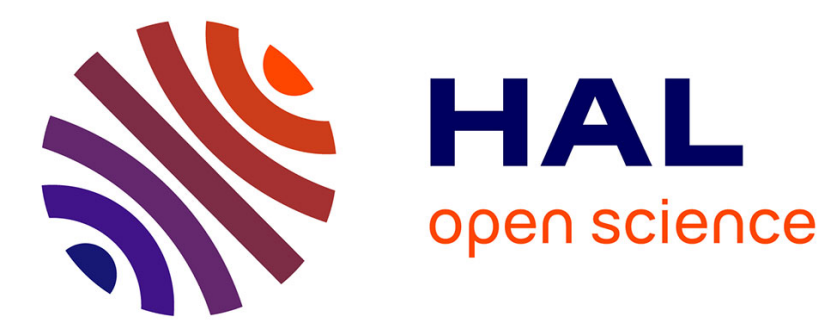

\title{
Experimental Investigation of the Linearization of an SOA based CO-OFDM System
}

Jacqueline E Sime, Pascal Morel, Mihai Telescu, Noël Tanguy, Stéphane Azou

\section{To cite this version:}

Jacqueline E Sime, Pascal Morel, Mihai Telescu, Noël Tanguy, Stéphane Azou. Experimental Investigation of the Linearization of an SOA based CO-OFDM System. IEEE Photonics Conference (IPC), Oct 2021, Vancouver (virtual), Canada. hal-03420595

\section{HAL Id: hal-03420595 \\ https://hal.univ-brest.fr/hal-03420595}

Submitted on 9 Nov 2021

HAL is a multi-disciplinary open access archive for the deposit and dissemination of scientific research documents, whether they are published or not. The documents may come from teaching and research institutions in France or abroad, or from public or private research centers.
L'archive ouverte pluridisciplinaire HAL, est destinée au dépôt et à la diffusion de documents scientifiques de niveau recherche, publiés ou non, émanant des établissements d'enseignement et de recherche français ou étrangers, des laboratoires publics ou privés. 


\title{
Experimental Investigation of the Linearization of an SOA based CO-OFDM System
}

\author{
$1^{\text {st }}$ Jacqueline E. Sime \\ Ecole Nationale d'Ingénieurs de Brest \\ Lab-STICC, CNRS, UMR 6285 \\ CS 73862-29238, Brest Cedex 3, France \\ jacqueline.sime@enib.fr \\ $4^{\text {th }}$ Noël Tanguy \\ Univ Brest \\ Lab-STICC, CNRS, UMR 6285 \\ F-29200 Brest, France \\ noel.tanguy@univ-brest.fr
}

\author{
$2^{\text {nd }}$ Pascal Morel \\ Ecole Nationale d'Ingénieurs de Brest \\ Lab-STICC, CNRS, UMR 6285 \\ CS 73862-29238, Brest Cedex 3, France \\ pascal.morel@enib.fr \\ $5^{\text {th }}$ Stéphane Azou \\ Ecole Nationale d'Ingénieurs de Brest \\ Lab-STICC, CNRS, UMR 6285 \\ CS 73862-29238, Brest Cedex 3, France \\ stephane.azou@enib.fr
}

\author{
$3^{\text {rd }}$ Mihai Telescu \\ Univ Brest \\ Lab-STICC, CNRS, UMR 6285 \\ F-29200 Brest, France \\ mihai.telescu@univ-brest.fr
}

\begin{abstract}
In this paper, we perform an experimental analysis of digital predistortion in the context of SOA based CO-OFDM systems for metropolitan/access networks. We conduct a comparative analysis of several pre-distorders including a novel structure called the Generalized Envelope Memory Polynomials.
\end{abstract}

\section{Index Terms}

Digital predistortion, CO-OFDM, Semiconductor Optical Amplifier, linearization, experimental

\section{INTRODUCTION}

Semiconductor Optical Amplifiers (SOAs) have been the object of recent research in optical communication systems for their reasonable cost, their ability for easy integration, and their wide optical bandwidth [1]. Similarly, Coherent Optical Orthogonal Frequency Division Multiplexing (CO-OFDM) systems are being explored notably since they can be easily implemented with the use of Digital Signal Processing (DSP) and they have capability for high spectral efficiency [2]. The combination of a non-constant envelope OFDM configuration and SOAs as amplifiers gives rise to nonlinearities. Digital predistortion (DPD) has been used in radio communications and most recently in photonics to counter these undesirable effects [3]. The present paper aims to provide further insight on the benefits of various predistorders through an experimental investigation.

\section{Digital Predistortion Algorithms}

Predistortion is based on the idea that when faced with the undesirable effects of a nonlinear function, one way to address it is to apply the inverse of that nonlinear function in order to cancel these effects. With low complexity being a crucial aspect in photonics, this paper chooses to deal with three simplified inspired versions of the Volterra Series predistorders [4] : the Memory Polynomials (MP), the Envelope Memory Polynomials (EMP), and the Generalized Memory Polynomials (GMP).

We propose a new memory polynomials DPD structure, the Generalized Envelope Memory Polynomials (GEMP), with the aim to provide an extra degree of freedom as is the case for the GMP but focusing solely on the signal's magnitude. The GEMP's mathematical expression is shown below:

$$
y_{G E M P}(n)=x(n)\left(c_{0}+\sum_{k=1}^{K_{a}} \sum_{l=0}^{L_{a}-1} a_{k l}|x(n-l)|^{k}+\sum_{p=1}^{K_{b}} \sum_{q=1}^{K_{c}} \sum_{m=1}^{M_{b}} \sum_{l=0}^{L_{b}-1} b_{p q m l}|x(n-l)|^{p} \cdot|x(n-l-m)|^{q}\right)
$$

The added value of the GEMP is that its use can be extended to other scenarios such as intensity-modulation/direct-detection. To find the appropriate structural parameters without performing an exhaustive search, this paper uses the Hill-Climbing heuristic [5]. The predistorders' coefficients are estimated using least squares approximation.

\section{EXPERIMENTAL SETUP}

The experimental setup used for this paper is depicted in Fig. 1. The input bit stream goes through a 4-QAM modulation. The 4-QAM symbols are coded into OFDM frames with a bandwidth of $8 \mathrm{GHz}$ consisting of 128 subcarriers. The effective data rate in this case is $11.12 \mathrm{Gbit} / \mathrm{s}$. Some hard-clipping at a $6 \mathrm{~dB}$ ratio is done on the time signal before being sent into the Keysight M8195A Arbitrary Waveform Generator (AWG) through a VISA connection. The $32 \mathrm{GSa} / \mathrm{s}$ digital-to-analog converters of the AWG have a resolution of 8 bits. The electro-optic conversion is done with the MXIQER-LN-30 optical 
modulator that has a $V_{\pi}$ of $5.4 \mathrm{~V}$ and the Keysight N4391A Optical Modulation Analyzer (OMA) local oscillator operating at $1540 \mathrm{~nm}$ with a laser linewidth of $100 \mathrm{kHz}$. The IQ modulator's operating point is stabilized via the MBC-IQ-LAB-A1 bias controller. The booster amplifier is a $750 \mu \mathrm{m}$ INPHENIX-IPSAD1501 SOA with a gain of $17 \mathrm{~dB}$, a noise figure of $9 \mathrm{~dB}$, and a supplied bias current of $240 \mathrm{~mA}$. The OMA performs the opto-electronic conversion with the $40 \mathrm{GSa} / \mathrm{s}$ analog-to-digital converters at a resolution of 8 bits, then sends the signal back into the computer by using the .NET interface. At the receiver, a lowpass filter with a $8.8 \mathrm{GHz}$ bandwidth is applied to reduce out-band noise. Then, the signal goes through synchronization, equalization, phase and amplitude tracking, and demodulation. For the purposes of this paper, the fiber is not included as the focus is to reduce the nonlinearities caused by the SOA at the emitter side.

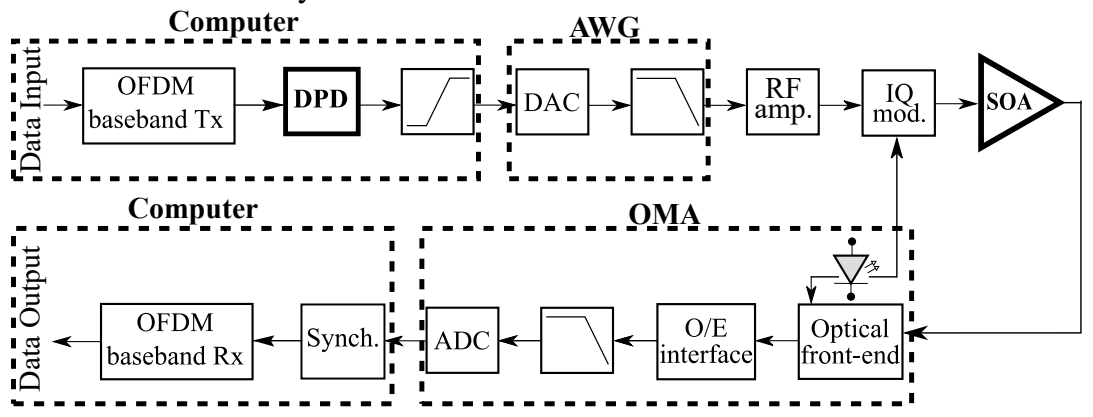

Fig. 1: CO-OFDM experimental setup. AWG: Arbitrary Waveform Generator, OMA: Optical Modulation Analyzer

IV. RESULTS

The results shown in this section were obtained by identifying the predistorders (MP, EMP, GMP, and GEMP) at different input powers of the SOA then validating the DPD by sending 32 frames at that same input power. The input power into the SOA is measured by taking the power going into the OMA in an optical back-to-back setting. Fig. 2a displays the mean Error Vector Magnitude (EVM) averaged from 5 different measurements. The aim in terms of EVM should be a limit of 30\% for the 4-QAM case [6] . It can be inferred that by using DPD the input power into the SOA can be increased from -15.75 $\mathrm{dBm}$ (no DPD) to $-14 \mathrm{dBm}$ (MP) and $-13 \mathrm{dBm}$ (EMP, GMP, and GEMP) while still meeting the EVM requirements. This corresponds to an increase in reach of $8.75 \mathrm{~km}$ (MP) and $13.75 \mathrm{~km}$ (EMP, GMP, and GEMP) for a single-mode fiber. As input power increases, the gain in performance from DPD becomes more apparent. Fig. $2 b$ provides the constellation of the

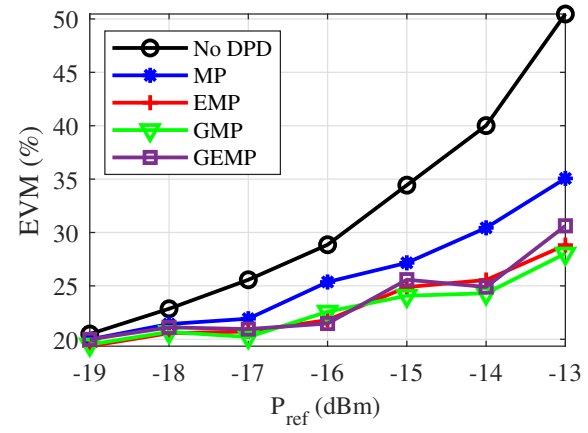

(a)

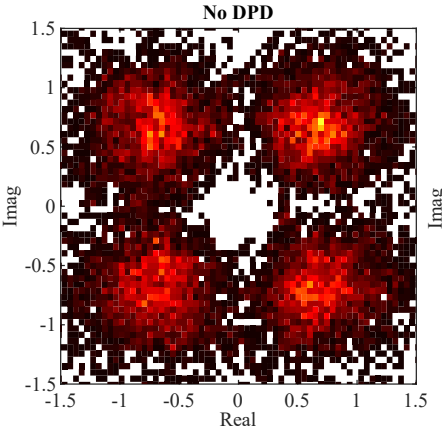

(b)

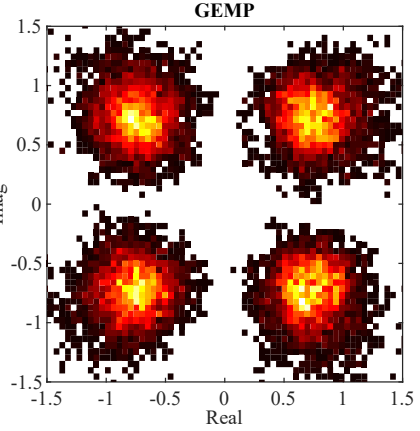

Fig. 2: (a) Error Vector Magnitude and (b) Constellation of the no DPD and GEMP cases at $P_{r e f}=-13 \mathrm{dBm}$

no DPD and GEMP cases at $P_{\text {ref }}=-13 \mathrm{dBm}$. The color code is an indication of density with the darkest color being the lowest density and the lightest color corresponding to the highest density. Using GEMP as an example for a no DPD versus with DPD comparison, a brighter constellation signifies a better quality of transmission with DPD compared to without DPD.

\section{CONCLUSiON}

The mitigation of nonlinear impairments caused by a booster SOA in a CO-OFDM network application was investigated experimentally. The effect of DPD is obvious with EMP, GMP, and GEMP performing better than MP.

\section{REFERENCES}

[1] R. Bonk, "SOA for Future PONs," IEEE OFC, pp. Tu2B-4, March 2018.

[2] O. Vassilieva et al.,"Reach extension with 32 and 64 GBaud single carrier vs. multi-carrier signals," IEEE OFC, Los Angeles, CA, USA, pp. 1-3, 2017.

[3] J. E. Sime, P. Morel, M. Telescu, N. Tanguy, S. Azou, "Digital Predistortion for CO-OFDM Systems Using Generalized Memory Polynomials," 8th IEEE Int. Conf. on Communications and Electronics (IEEE ICCE 2020), Phu Quoc Island, Vietnam, Jan. 13-15th 2021.

[4] F. M. Ghannouchi et al., Behavioral Modeling and Predistortion of Wideband Wireless Transmitters, 1st ed. Chichester, UK: Wiley, 2015.

[5] S. Wang, et al., "Optimal sizing of generalized memory polynomial model structure based on hill-climbing heuristic," IEEE 46th EuMC, London, UK, 2016, pp. 190-193.

[6] R. Schmogrow et al., "Error vector magnitude as a performance measure for advanced modulation formats," IEEE Photonics Technology Letters, vol. 24, no. 1, pp. 61-63, Oct. 2011. 